\title{
YELLOW PITAYA (HYLOCEREUS MEGALANTHUS) FATTY ACIDS COMPOSITION FROM ECUADORIAN AMAZONIA
}

\author{
Altuna JL ${ }^{1}$, Silva $\mathbf{M}^{2}$, Álvarez $\mathbf{M}^{2}$, Quinteros $\mathbf{M F}^{1}$, Morales $\mathrm{D}^{2}$, Wilman Carrillo ${ }^{1,2 *}$ \\ ${ }^{1}$ Department of Research, Faculty of Agricultural Sciences, Natural Resources and the Environment, Bolıvar State University, Av. Ernesto \\ Che Guevara s/n-Av. Gabriel Secaira, (CP 020150), Guaranda, Ecuador. ${ }^{2}$ Laboratory of Functional Foods, Faculty of Foods Science and \\ Engineering, Technical University of Ambato, Av. Los Chasquis y Rio Payamino, Campus Huachi, (CP 1801334) Ambato, Ecuador. \\ Email: wi.carrillo@uta.edu.ec
}

Received: 23 January 2018, Revised and Accepted: 07 July 2018

\section{ABSTRACT}

Objective: The aim of this study was to determine the composition of methyl esters fatty acids (FAMEs) in yellow pitaya (Hylocereus megalanthus) seeds cultivated in the Palora, Ecuador Amazonian region.

Methods: Yellow pitaya oil was obtained from yellow pitaya seeds using the Soxhlet technique. FAMEs identification and quantification were carried out using the gas chromatography (GC) with mass spectrometry (MS) and the database Library NIST14.L to identify the FAMEs present in yellow pitaya oil.

Results: Yellow pitaya oil from Ecuador Amazonian region was analyzed by GC-MS, to obtain the five main fatty acids, palmitic acid (11.52\%), stearic acid (4.29\%), oleic acid (11.09\%), vaccenic acid (3.08\%), and linoleic acid (69.98\%). Omega 6 was the most abundant fatty acid, total content in yellow pitaya seeds oil.

Conclusions: Yellow pitaya seeds content a good proportion of polyunsaturated fatty acids (omega 6). For their fatty acid composition, yellow pitaya seeds can be considered as healthy food and can be used in the food industry for different purposes. Regular consumption of yellow pitaya can improve human health.

Keywords: Dragon fruit, Yellow pitaya, Fatty acid, Methyl esters fatty acids, Lipids.

(c) 2018 The Authors. Published by Innovare Academic Sciences Pvt Ltd. This is an open access article under the CC BY license (http://creativecommons. org/licenses/by/4. 0/) DOI: http://dx.doi.org/10.22159/ajpcr.2018.v11i11.24922

\section{INTRODUCTION}

Yellow pitaya (Hylocereus megalanthus), also named dragon fruit, belongs to the Cactaceae family. This plant is a native of Mexico, Central and South America (Colombia, Peru, Venezuela, and Ecuador) [1]. In these countries, different cactus fruit crops are marketed as yellow pitaya, including the species Acanthocereus pitajaya, Selenicereus megalanthus, Acanthocereus colombianus, Hylocereus triangularis, and H. megalanthus [2,3]. Dragon fruit is cultivated in many countries in Asia such as Taiwan, Vietnam, Philippines, and Malaysia, due to their high acceptation as an exotic fruit [3,4]. Red pitaya has been described with antioxidant and antiproliferative activities. Antioxidant activity was determined using DPPH and ABTS methods, obtaining values of EC50, $22.4 \pm 0.29$, and $118 \pm 4.12 \mu \mathrm{mol}$ Vitamin C equivalents/g for the flesh and the peel dried extract and $28.3 \pm 0.83$ and $175 \pm 15.7 \mu$ mol of Trolox equivalents antioxidant capacity/g for the flesh and for the peel dried extract. The antiproliferative study on B16F10 melanoma cells revealed that the peel (EC50 $25.0 \mu \mathrm{g}$ of peel matter) component was a stronger inhibitor of the growth of B16F10 melanoma cancer cells than the flesh [5]. Pitaya seeds also have a content of oil like most grain seed, such as flaxseed, canola, sesame seed, quinoa seed, and grape seed. In common bean, Phaseolus vulgaris, protein concentrate, antioxidant activity, and zebrafish larvae. In the cactus plant, the most important fruit pigments are the betacyanins and betaxanthins. Betalains compounds, content red-violet betacyanin and yellow betaxanthins, these compounds are water-soluble pigments that provide colors in flowers and fruits. The known betacyanin pigments of Hylocereus polyrhizus flesh are betanin, named as phyllocactin and a recently discovered betacyanin, hylocerenin Betanin, from red beet, effectively inhibited lipid peroxidation, and heme decomposition, suggesting that these pigments may provide protection against certain oxidative stress-related disorders [6-8]. Oil is obtained when the mucin surmounting the seeds is retired, and oil is extracted from these seeds. Oil of these seeds has a high content of linoleic acid (omega 6) fatty acid which is an essential fatty acids, EFAs, as the human body cannot synthesize this EFA $[9,10]$. In Ecuador, 500 hectares are dedicated to the crop of yellow pitaya in the Amazonian region cantón palora.

In 2015, Ecuador exported to different countries 344 mil ton of yellow pitaya valued at 3.2 million USD. Yellow pitaya is an important crop for Ecuador from the economic point of view. The aim of this study was to characterize the composition of fatty acids methyl esters (FAMEs) present in yellow pitaya oil samples cultivated in this Amazonian region of Ecuador using a gas chromatography-mass selective detector (GC-MSD).

\section{METHODS}

\section{Oil extraction}

Yellow pitaya (H. megalanthus) was obtained from FINCA PROCEL in Palora-Ecuador Amazonian region. Yellow pitaya oil sample was obtained using a Soxhlet apparatus for approximately $5 \mathrm{~h}$ with hexane as solvent, with a solid to solvent ratio of $1 / 7 \mathrm{~m} / \mathrm{v}$. After the extraction process, the flask contents were filtered, and the liquid fraction containing the lipid extract and solvent was poured into a $250-\mathrm{mL}$ flask of a rotary film evaporator to remove the solvent. The obtained oil was collected, evaporated under nitrogen, weighed, and stored in sealed amber glass vials at $-20^{\circ} \mathrm{C}$ until analysis [11]

\section{Fatty acids analysis by GC-MSD}

The fatty acid composition of oil extracted from yellow pitaya seeds was analyzed by injecting fatty acid methyl esters $[12,13]$ into an Agilent Technologies 7980A system Gas Chromatography (Agilent, Santa Clara, CA) equipped with a Mass Selective Detector 5977A GC/MSD (Agilent, 
Santa Clara, CA), an autosampler 7693, column (60 m $\times 250 \mu \mathrm{m} \times$ $0.25 \mu \mathrm{m}$, Agilent $122-7062$ ). The oven temperature ramp 2: At $200^{\circ} \mathrm{C}$ at $25^{\circ} \mathrm{C} / \mathrm{min}$ for $10 \mathrm{~min}$; ramp 3: At $250^{\circ} \mathrm{C}$ at $2^{\circ} \mathrm{C} / \mathrm{min}$. The injector and detector temperatures were set at $250^{\circ} \mathrm{C}$. Helium was used as carrier gas at a linear flow velocity of $1.4 \mathrm{~mL} / \mathrm{min}$. All assays were made in triplicate $(n=4)$.

\section{RESULTS}

Yellow pitaya fruits used in this study were cultivated in the company FINCA PROCEL in Palora-Ecuador, Amazonia region (Fig. 1a and b). Fig. 1c shows yellow pitaya fruits in pitaya tree with their thorns. Fig. 1d shows yellow pitaya fruit without thorns. Fig. 1e shows yellow pitaya list for exportation after quality control.

FAMEs from yellow pitaya seeds ( $H$. megalanthus) were analyzed using the GC-MS method, and the identification of fatty acids was made using the spectrum of a database Library NIST14.L. The GC chromatogram presents five abundant peaks separated with an excellent resolution of each peak with the help of a column Agilent DB-WAX 122-7062 and were identified with a Mass Selective Detector 5977A GC/MSD (Agilent,

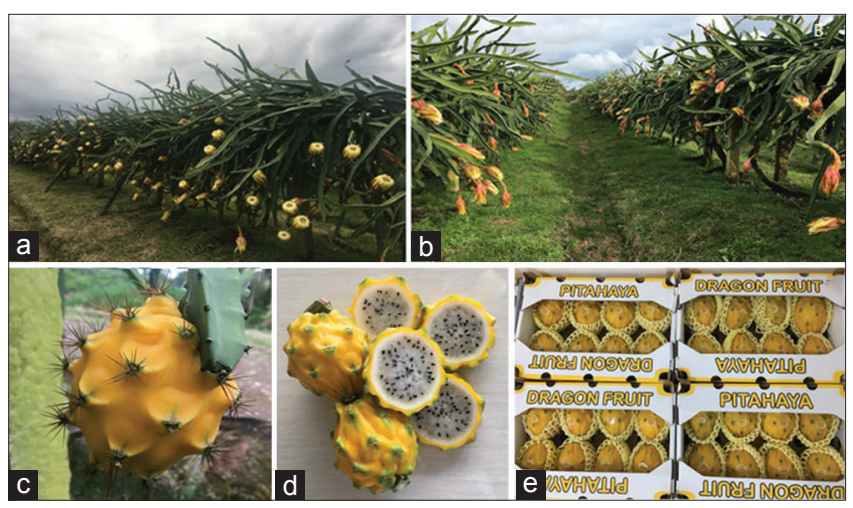

Fig. 1: Photographs of dragon fruit (yellow pitaya) grown in Ecuador. ( $a$ and b) Cultivar of FINCA PROCEL (Palora and Ecuador), (c and d) yellow pitaya fruit, and (e) yellow pitaya fruits with export packaging
Santa Clara, CA). Fig. 2 shows the peaks observed in the chromatogram after analysis with the GC/MS. The first peak presents a retention time of $13.779 \mathrm{~min}$ and was identified as C16:0, the second peak presents a retention time of $16.469 \mathrm{~min}$ and was identified as C18:0, the third peak presents a retention time of $17.203 \mathrm{~min}$ and was identified as C18:1, the fourth peak presents a retention time of $17.324 \mathrm{~min}$ and was identified as C18:1 trans, and finally the fifth peak presents a retention time of 18.367 minutes and was identified as C18:2. The separation and definition of the five relevant peaks were excellent in the GC chromatogram obtained.

The concentration of FAMEs present in yellow pitaya seeds was determined using the peak area ratio with the help of the instrument software. Table 1 shows the percentage of main fatty acids of yellow pitaya seeds oil. C16:0 presents a value of $11.52 \%$ of palmitic acid, total content, C18:0 shows a $4.29 \%$ of stearic acid, C18:1 presents a value of $11.09 \%$ of oleic acid, total content, C18:1 trans 11 shows a $3.08 \%$ vaccenic acid, and C18:2 presents a value of $69.98 \%$ of linoleic acid, total content. Yellow pitaya oil from Amazonian of Ecuador presents a high content of polyunsaturated fatty linoleic acid.

Figure 3a-d shows a typical mass spectrum of palmitic acid, stearic acid, oleic acid, vaccenic acid, linoleic acid, and linolenic acid. They present a typical fragmentation of ions in the mass spectrum. These mass spectrums were used to identify the structural formula and chemical name of fatty acids in yellow pitaya (H. megalanthus).

\section{DISCUSSION}

Vegetal oils are rich in fatty acids. Fatty acids can be classified into three groups (1) saturated fatty acids (SFAs), (2) monounsaturated fatty acids (MUFAs), and (3) polyunsaturated fatty acids (PUFAs). Unsaturated fatty acids have a special group named omega designed with letter Greek ( $\omega$ ) which indicates the position of last carbon of the cadent opposite to the functional carboxylic group. For example, $\omega-9$ has a first double bond between C9 and C10. Omega $9(\omega-9)$ oleic acid is a non-essential fatty acids (NEFAs) not being essential to the human body [14]. Omega $6(\omega-9)$ linoleic acid and omega $3(\omega-3)$ linolenic acid are Essential Fatty Acids, as those acids cannot can be synthesized by the human body and they need to be incorporated in the food diet. The fatty acid NEFAs, EFAS, SFAs, MUFAs, and PUFAs profiles in vegetable

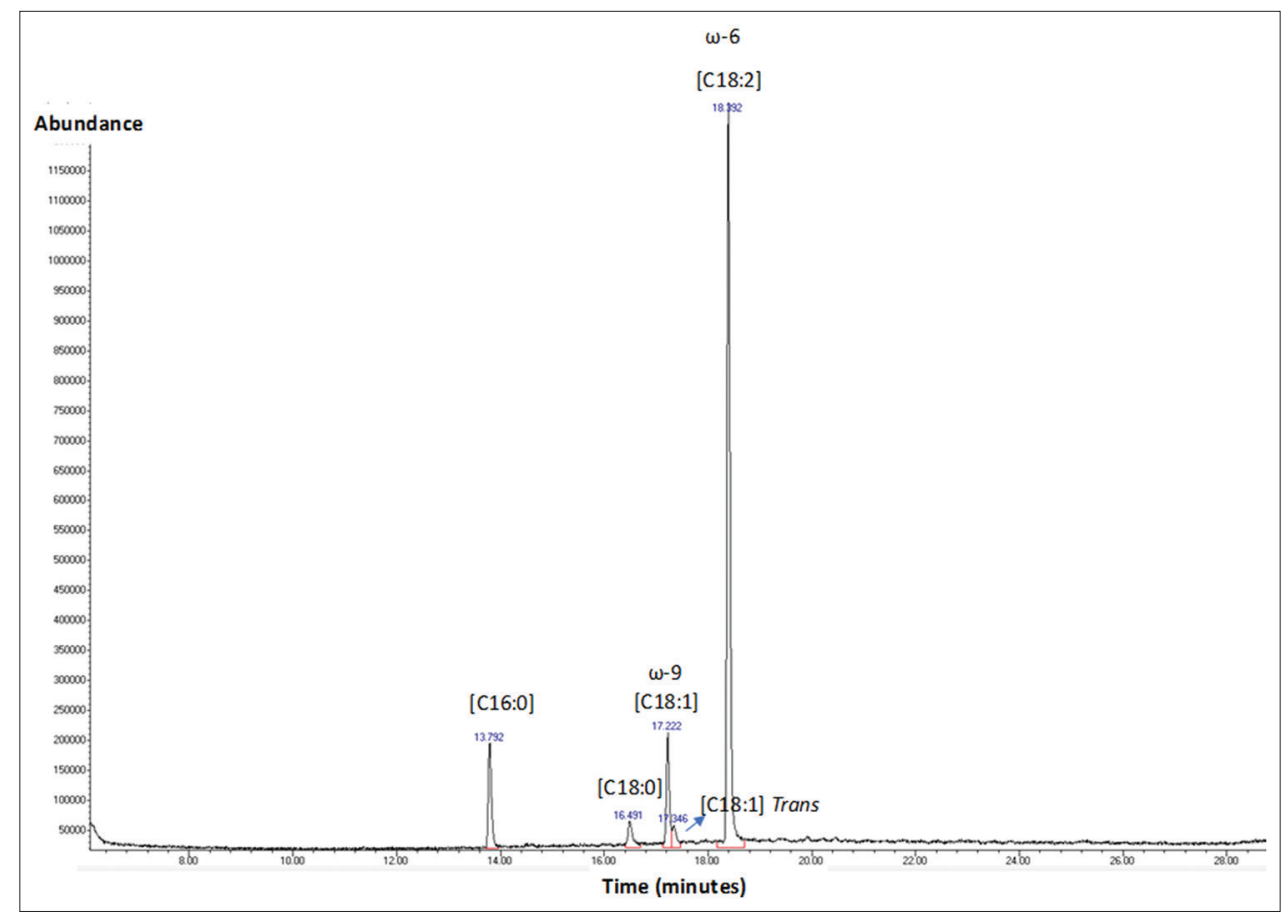

Fig. 2: Gas chromatography chromatogram of methyl esters fatty acids of yellow pitaya from Ecuador 
oils are then very important to know $[15,16]$. With the fatty acid profile, we can evaluate the value of each oil in terms of health, technology, and economy. PUFAS are reported being able to reduce cholesterol levels and be used to the prevention of cardiovascular risk. In the market, consumers appreciate vegetable oils with a high content of omega 3,6 , and 9. These oils are considered healthy and appropriate for a healthy diet. From the technology point of view, good content of MUFA, such as the one of olive oil, allows high stability in lipid oxidation. On the other hand, vegetable oils rich in PUFAs with a high degree of unsaturation are susceptible of an oxidation process with a deterioration of the vegetable oil. Vegetable oil with a high content of MUFAs is most expensive due to their high stability with a high degree of $\alpha$-tocopherol natural antioxidant in oils. Yellow pitaya oil has a high content of omega $6(69.98 \%)$, these results are in accordance with other authors. Ariffin et al., 2009, reported content of red pitaya with a value of $49.6 \%$ of linoleic acid (H. polyrhizus) and 50.1\% of linoleic acid (Hylocereus undatus) [17]. We can observe that the percentage of linoleic acid in yellow pitaya is higher than in the two species of red pitaya from Malaysia. Yellow pitaya oil, due to its high content of omega 6, can be marketed as healthy vegetable oil and can be used in the food industry to manufacture functional foods. Rui et al., 2009, reported a fatty acids profile in white pitaya of Malaysia. FAMEs of pitaya oil were extracted by different methods. Linoleic acid presented values of $33.31 \%$ (Soxhlet extraction method), 25.22\% (Microwave-assistant extraction method),

Table 1: Fatty acids composition of yellow pitaya seeds oil (H. megalanthus)

\begin{tabular}{lll}
\hline FAMEs & Number of carbons & \% Peak area \\
\hline Palmitic acid & C16:0 & $11.52 \pm 0.85$ \\
Stearic acid & C18:0 & $4.29 \pm 0.41$ \\
$\sum$ SFA & & $15.81 \pm 1.26$ \\
Oleic acid & C18:1 $18: 1$ trans 11 & $11.09 \pm 0.77$ \\
Vaccenic acid & C11 & $3.08 \pm 0.18$ \\
$\sum$ MUFA & & $14.17 \pm 0.95$ \\
Linoleic acid & C18:2 & $69.98 \pm 1.49$ \\
$\sum$ PUFA & & $69.98 \pm 1.49$ \\
\hline
\end{tabular}

SFA: Saturated fatty acid, MUFA: Monounsaturated fatty acid and PUFA: Polyunsaturated fatty acid. Data are expressed as the mean \pm standard deviation $(n=4)$. FAMEs: Methyl esters fatty acids
35.73\% (Aqueous enzymatic extraction method), 40.15\% (Microwaveassistant extraction/Aqueous enzymatic extraction method), and $54.43 \%$ (supercritical fluid extraction method), respectively [18]. The result of the linoleic acid obtained in our study (69.98\%) is higher than Rui et al., 2009 results obtained in white pitaya.

Liaotrakoon et al., 2013, reported content of linoleic acid (45-55\%) of pitaya oil (Hylocereus spp.) our linoleic acid value is also higher than these values [19]. Lim et al., 2010, reported the composition of FAMEs in two species of dragon fruit (red pitaya), they reported a content of red pitaya of $48.0 \%$ of linoleic acid (H. polyrhizus) and $55.63 \%$ of linoleic acid (H. undatus) [20]. It can be observed that the percentage of linoleic acid in yellow pitaya is higher than the value obtained in the two species of red pitaya from Malaysia. When the content of omega 6 (C18:2) of pitaya oil with other vegetable oils produced in Ecuador, it can be observed that only kahai oil (Caryodendron orinocense Karst) and tocte oil Uuglans neotropical Diels) have a high content of omega 6 with values of $68.04 \%$ and $65.81 \%$, respectively. Pitaya oil presents a higher value of omega 6 than both oils with a value of $69.98 \%$ [21,22]. On the other hand, pitaya oil has a higher content of palmitic acid than previously mentioned oils. Pitaya oil presents $11.52 \%$ of palmitic acid while kahai oil has a value of $7.0 \%$ of palmitic acid and tocte oil $5.05 \%$ of palmitic acid. The content of SFAs in pitaya oil was slightly higher than in kahai and tocte oils. Other vegetable oils from Ecuador presenting low content of omega 6 than pitaya oil are corn oil (Zea mays L.) with a value of $52.68 \%$ of omega 6 [13], sacha inchi (Plukenetia volubilis L.) with a value of $34.98 \%$ of omega 6 [23], sambo oil (Cucurbita ficifolia L) with a value of $33.98 \%$ of omega 6 [24], chia oil (Salvia hispanica L.) with a value of $31.03 \%$ of omega 6 [11], macadamia oil (Macadamia intergrifolia) with a value of $3.79 \%$ of omega 6 [12], and ungurahua oil (Oenocarpus bataua) with a low value of $1.60 \%$ of omega 6 [25]. In the production of pitaya pulp for export tons of seeds are generated as food waste. Obtaining oil from these seeds can be an alternative use for these companies. Bearing in mind that pitaya oil has a high omega 6 content, it could be considered a healthy oil with possibilities to use in food, cosmetic, and pharmaceutical industries in Ecuador.

\section{ACKNOWLEDGMENTS}

This study was supported by Universidad Técnica de Ambato, Ecuador (Project CPU-1373-2014-UTA) and (Project Canje de Deuda EspañaEcuador). This work has been reviewed in the English edition by

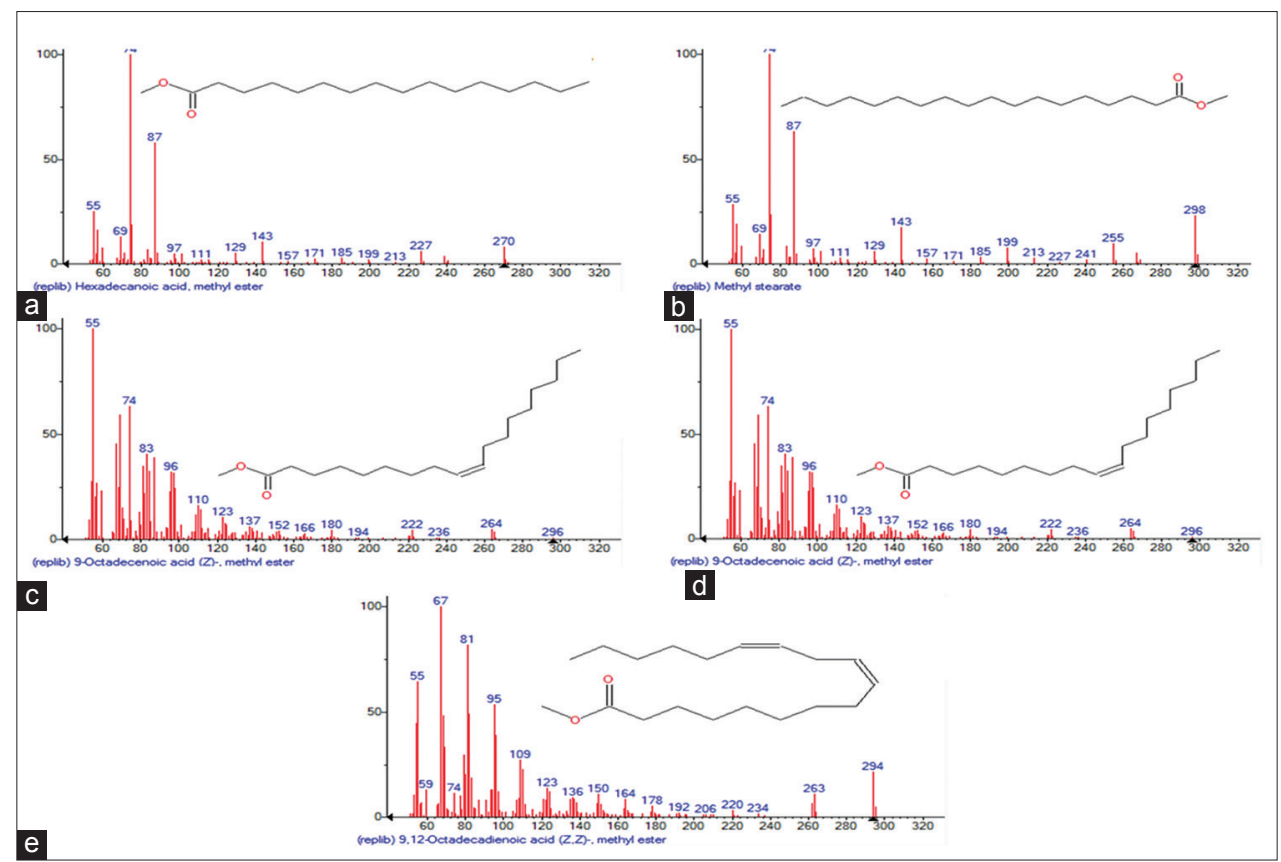

Fig. 3: Mass spectrum of methyl esters fatty acids from yellow pitaya. (a) Mass spectrum of palmitic acid, (b) mass spectrum of stearic acid, (c) mass spectrum of oleic acid, (d) mass spectrum of vaccenic acid, and (e) mass spectrum of linoleic acid 
Emilio Labrador. Thanks, at Freddy Procel owner of the company of exportation FINCA PROCEL in Palora, Ecuador, to supply yellow pitaya fruit for this study.

\section{AUTHORS' CONTRIBUTIONS}

Carrillo W, Altuna JL, Quinteros MF, and Morales D conceived and designed the experiments. Silva $\mathrm{M}$ and Alvarez $\mathrm{M}$ performed the gas chromatography analyses. Carrillo W wrote the paper.

\section{CONFLICTS OF INTEREST}

The authors declare no conflicts of interest.

\section{REFERENCES}

1. Ramírez-Truque C, Esquivel P, Carle R. Neutral sugar profile of cell wall polysaccharides of pitaya (Hylocereus sp.) fruits. Carbohydr Polym 2011;83:1134-8.

2. Pagliaccia D, Vidalakis G, Douhan GW, Lobo R, Tanizaki G. Genetic characterization of pitahaya accessions based on amplified fragment length polymorphism analysis. HortScience 2015;50:332-6.

3. Narváez-Cuenca CE, Espinal-Ruiz M, Restrepo-Sánchez IP. Heat shock reduces both chilling injury and the overproduction of reactive oxygen species in yellow pitaya (Hylocereus megalanthus) fruits. J Food Qual 2011;34:327-32.

4. Gunasena HP, Pushpakumara DK, Kariyawasam M. Dragon Fruit Hylocereus undatus (Haw.) Britton and Rose. In: Underutilized Fruit Trees in Sri Lanka. New Delhi: World Agroforestry Centre; 2007. p. $110-42$.

5. Wu LC, Hsu HW, Chen YC, Chiu CC, Lin YI, Ho JA. Antioxidant and antiproliferative activities of red pitaya. Food Chem 2006;95:319-27.

6. Cai Y, Sun M, Corke H. Antioxidant activity of betalains from plants of the Amaranthaceae. J Agric Food Chem 2003;51:2288-94.

7. Wybraniec S, Platzner I, Geresh S, Gottlieb HE, Haimberg M, Mogilnitzki M, et al. Betacyanins from vine cactus Hylocereus polyrhizus. Phytochemistry 2001;58:1209-12.

8. Wybraniec S, Mizrahi Y. Fruit flesh betacyanin pigments in Hylocereus cacti. J Agr Food Chem 2002;50:6086-9.

9. Arumugam M, Raman M, Eagappan K. Formulation and storage stability of beta carotene enriched vitamin d3 and omega 3 fortified cold pressed virgin coconut oil. Int J Pharm Pharm Sci 2014;6:112-6.

10. Dhifi W, Khedher M, Bellili S, Sadaka C, Wakim L, Beyrouthy M, et al. Effects of olive drying and storage on the oxidative status, aroma, chlorophyll and fatty acids composition of olive oil. Int J Pharm Pharm Sci 2014;7:102-8.

11. Carrillo W, Cardenas M, Carpio C, Morales D, Álvarez M, Silva M.
Content of nutrients component and fatty acids in chia seeds (Salvia hispánica L.) cultivated in Ecuador. Asian J Pharm Clin Res 2018;11:384-390.

12. Carrillo W, Carpio C, Morales D, Vilcacundo E, Alvarez M. Fatty acids composition in Macadamia seeds oil (Macadamia intergrifolia) from Ecuador. Asian J Pharm Clin Res 2017;10:303-6.

13. Carrillo W, Carpio C, Morales D, Vilcacundo E, Alvarez M, Silva M. Content of fatty acids in corn (Zea mays L.) oil from Ecuador. Asian J Pharm Clin Res 2017;10:150-3.

14. Zambiazi RC, Przybylski R, Zambiazi MW, Mendonça CB. Fatty acid composition of vegetable oils and fats. B. CEPPA Curitiba 2007;25:111-20

15. Moyad MA. An introduction to dietary/supplemental omega-3 fatty acids for general health and prevention. Part I. Urol Oncol 2005;23:28-35.

16. Wilson TA, Ausman LM, Lawton CW, Hegsted DM, Nicolosi RJ. Comparative cholesterol lowering properties of vegetable oils: Beyond fatty acids. J Am Coll Nutr 2000;19:601-7.

17. Ariffin AA, Bakar J, Tan CP, Rahman RA, Karim R, Loi CC. Essential fatty acids of pitaya (dragon fruit) seed oil. Food Chem 2009;114:561-4.

18. Rui H, Zhang L, Li Z, Pan Y. Extraction and characteristics of seed kernel oil from white pitaya. J Food Eng 2009;93:482-6.

19. Liaotrakoon W, De Clercq N, Van Hoed V, Dewettinck K. Dragon fruit (Hylocereus spp.) seed oils: Their characterization and stability under storage conditions. J Am Oil Chem Soc 2013;90:207-15.

20. Lim HK, Tan CP, Karim R, Ariffin AA, Bakar J. Chemical composition and DSC thermal properties of two species of Hylocereus cacti seed oil: Hylocereus undatus and Hylocereus polyrhizus. Food Chem 2010;119:1326-31

21. Carrillo W, Greffa J, Vinueza D, Álvarez M, Silva M, Carpio C, et al. Fatty acids content of kahai (Caryodendron orinocense karst) seeds cultivated in amazonian of Ecuador. Asian J Pharm Clin Res 2017; 10:399-402.

22. Vilcacundo E, Alvarez M, Silva M, Carpio C, Morales D, Carrillo W. Fatty acids composition of tocte (Juglans neotropica Diels) walnut from Ecuador. Asian J Pharm Clin Res 2018;11:395-8.

23. Carrillo W, Quinteros MF, Carpio C, Morales D, Vásquez G, Alvarez M, et al. Identification of fatty acids in Sacha inchi oil (Cursive Plukenetia volubilis L.) from Ecuador. Asian J Pharm Clin Res 2018;11:379-81.

24. Carrillo W, Carrillo C, Carpio C, Morales D, Vilcacundo E, Alvarez M, et al. Characterization of fatty acids in sambo oil (Cucurbita ficifolia L.) from Ecuador. Asian J Pharm Clin Res 2018;11:403-6.

25. Carrillo W, Carpio C, Morales D, Alvarez M, Silva M. Fatty acids content in ungurahua oil (Oenocarpus bataua) from Ecuador findings on adulteration of ungurahua oil in Ecuador. Asian J Pharm Clin Res 2018;11:391-4. 